\title{
AS FUNÇÕES EXECUTIVAS EM ALUNOS COM TRANSTORNO DO TDAH NA EDUCAÇÃO BÁSICA
}

\section{ARTIGO ORIGINAL}

GARCIA, Denise Fiuza ${ }^{1}$

RÊGO, Gabriel Gaudencio do ${ }^{2}$

GARCIA, Denise Fiuza. RÊGO, Gabriel Gaudencio do. As funções executivas em alunos com transtorno do TDAH na educação básica. Revista Científica Multidisciplinar Núcleo do Conhecimento. Ano 05, Ed. 01, Vol. 10, pp. 24-56. Janeiro de 2020. ISSN: 2448-0959

\section{RESUMO}

A realização desta pesquisa é direcionada para profissionais da área da saúde e educação, pesquisadores e pais que buscam compreender e se dedicar ao conhecimento do TDAH para proporcionar qualidade de vida nas esferas sociais e proporcionar estratégias para alcançar seus objetivos educacionais e profissionais. A pesquisa discorre as relações e implicações das disfunções executivas no portador do Transtorno de déficit de atenção e hiperatividade (TDAH) na conjuntura escolar apresenta os dilemas enfrentados para executar tarefas elaboradas que demandam o bom funcionamento das funções executivas para obter sucesso na realização das referidas. O TDAH apresenta como característica proeminentes a desatenção, a agitação e a impulsividade. Ele pode ser classificado em três subtipos: o predominante desatento, o predominante hiperativo-impulsivo e o predominante combinado. Cada

${ }^{1}$ Mestrado em andamento em Educação, Arte e História da Cultura. Especialização em andamento em Neurociências e psicologia aplicada. Especialização em Orientação Educacional. Graduação em Pedagogia.

2 Doutorado em Distúrbios do Desenvolvimento. Mestrado em Distúrbios do Desenvolvimento. Especialização em Neuropsicologia. Graduação em Psicologia. 
um possui suas próprias singularidades que refletem influências nas esferas familiar, social e escolar proporcionando dificuldades nas realizações das funções executivas. O assunto será tratado através de uma revisão sistemática com embasamento bibliográfico através de literaturas, revistas, jornais, artigos de revisão e experimentais tais como as teses que se encontram disponíveis para pesquisa. O objetivo é apresentar a importância do treino das funções executivas no portador de TDAH para melhor desempenho no contexto escolar e social.

Palavras-chave: Funções executivas, TDAH, desempenho escolar, educação Básica.

\section{INTRODUÇÃO}

O Transtorno do déficit de atenção e hiperatividade (TDAH), segundo a Associação Brasileira do Déficit de Atenção (ABDA) é uma alteração neurobiológica de origem genética, que pode ter início na infância, sendo capaz de permanecer por toda a sua vida. Ele se tipifica pelos os sintomas de desatenção, inquietude e impulsividade. $O$ transtorno é mais frequente em crianças e adolescentes, segundo apontado pelo Manual diagnóstico e estatístico de transtornos mentais (DSM-5). Ele ocorre na maioria das culturas com percentual de $5 \%$ nas crianças e $2,5 \%$ nos adultos aproximadamente, sendo que, a mais da metade dos casos o transtorno permanece até a vida adulta.

A princípio, apresenta-se uma revisão sistemática da literatura que inclui a conceituação do TDAH de acordo com o CID-10 e o DSM-5, a sua etiologia e sua epidemiologia. Igualmente conceituaremos as funções executivas e como elas se desenvolvem ao longo da educação da Educação Básica fazendo uma comparação das suas relações com o sucesso ou os insucessos da vida escolar.

O portador do TDAH usualmente apresenta problemas nas esferas da vida social, educacional e profissional. Malloy-Dinis et al. (2010) através de pesquisas e experiências clínicas apontam que os pacientes pediátricos com TDAH podem apresentar disfunções nas funções executivas. Willcutt (2005) também menciona que um dos principais indicadores do TDAH é a disfunção executiva, que leva o portador 
a apresentar comprometimentos nas realizações de tarefas e de tomada de decisão. Contudo, o portador do TDAH contém algumas dificuldades cognitivas que podem comprometer o processo de ensino e aprendizagem no âmbito escolar.

As funções executivas conceituam-se por um conjunto de capacidades que nos permitem a executar as ações necessárias para programar e atingir um objetivo concluir tarefas (COSENZA e GUERRA, 2011). Nesta conjuntura, as funções executivas compõem um mecanismo de controle cognitivo que direciona e coordena o comportamento humano de maneira adaptativa, possibilitando mudanças rápidas e flexíveis diante de novas exigências do ambiente (ALMEIDA, 2019). As funções executivas são habilidades que abrangem um conjunto de operações cerebrais constituídas pela a memória de trabalho, a atenção seletiva, o controle inibitório, o planejamento, o monitoramento e a flexibilidade cognitiva. Estas habilidades envolvem a regulação comportamental e colaboram para os processos cognitivos e adaptativos mediante as novas experiências (DIAS, 2009).

O presente trabalho tem como objetivo apresentar o TDAH e suas alterações no funcionamento executivo que ocasiona prejuízos nas habilidades do autocontrole, do planejamento, da memória de trabalho, da atenção e das metacognições. Estas habilidades encontram-se integradas às funções executivas e nos habilitam a tomada de decisões, a organizar tarefas diárias, a planejar e executar objetivos de longo e curto prazo, a manter o foco, a controlar os impulsos e a concluir tarefas de curto e longo prazo. Entretanto, as disfunções nas funções executivas provocam uma série de dificuldades que incluem um comportamento estereotipado com a dificuldade de assimilar novos repertórios cognitivos e comportamentais acarretando uma série de problemas no seu desenvolvimento cognitivo e social.

\section{FUNDAMENTAÇÃO TEÓRICA}

Pontua-se o início dos estudos sobre a hiperatividade segundo Barkley (2008), que desde 1865 o médico Heinrich Hoffman apresentava em seus escritos as experiências de suas práticas clínicas referente as doenças com as características do TDAH, apontadas como doenças típicas da infância. Porém, os créditos científicos referente 
ao transtorno foram dedicados a George Still e Alfred Tredgold mencionados como pioneiros nos estudos clínicos do TDAH. No século XX os estudos da neurologia e da psicologia da aprendizagem apontam a existências de crianças com dificuldades de reter informações, a falta de constância e com o comportamento agitado (KAEFER, 2008; MARTINEZ-BADÍA, 2015; DE VINUESA FERNÁNDEZ, 2017).

Caliman (2008) ressalta que na década de 90 a neurociência e a psicologia trouxeram uma nova construção para a interpretação do TDAH. Barkley (2008) é tido como uma das autoridades do campo do TDAH através dos seus estudos genéticos neuroquímicos dos sistemas neurotransmissores. Em 1993 o transtorno entrou para o CID 10 denominado como o Transtorno Hipercinético. (ROTTA et al., 2008) Atualmente é diagnosticado como transtorno do TDAH de acordo com o CID-10 e DSM-5.

No DSM-5 a conceituação do TDAH de acordo com o CID-10, a sua etiologia e a sua epidemiologia atribuíram três características, sendo elas: (1) A desatenção, que é expressada através dos comportamentos como a falta de persistência, a divagação na realização das tarefas, a desorganização e a dificuldade para manter o foco. (2) A hiperatividade que é marcada pela atividade motora excessiva e inquietude extrema. (3) A impulsividade que reflete o desejo das recompensas imediatas e incapacidade de postergar e apresentar a gratificação. O TDAH é subdividido por uma tríade: (1) tipo predominante desatento, (2) tipo predominante hiperativo-impulsivo e (3) tipo predominante combinado.

Para o TDAH é complexo gerenciar a atenção sustentada, igualmente é vulnerável a resposta ao longo prazo e apresenta uma mal execução da função executiva (MALLOY-DINIS et al., 2010; ABREU et al.; 2010; COSENZA e GUERRA, 2011). Contudo, denota que o TDAH apresenta um baixo rendimento escolar que provêm da dificuldade de controlar as suas impulsividades, a sua ansiedade e o insucesso de concluir as funções executivas com êxito.

Em segundo lugar trataremos das funções executivas, as quais constituem um conjunto de habilidades que nos permitem executar as ações necessárias para 
programar e atingir um objetivo, como também, executar e concluir as tarefas que nos são propostas ao longo da vida. (COSENZA e GUERRA, 2011; FUSTER, 2008). Nesta conjuntura, elas compõem um mecanismo de controle cognitivo que têm a função de direcionar e coordenar o comportamento humano de maneira adaptativa. Elas possibilitam as mudanças rápidas e flexíveis diante de novas exigências do ambiente vivenciado (ALMEIDA, 2019). As funções executivas são habilidades que abrangem um conjunto de operações de circuitos cerebrais contempladas por: a memória de trabalho, a atenção seletiva, o controle inibitório, a flexibilidade cognitiva, o planejamento e o monitoramento. Estas habilidades envolvem a regulação comportamental e contribuem para os processos cognitivos e adaptativos mediante o aprendizado (DIAS, 2009).

Diamond (2016) visualiza as funções executivas como uma família repleta de habilidades que dependem do circuito neural do córtex pré-frontal que desempenha um papel central e indispensável para a concentração, 0 pensamento e 0 gerenciamento dos impulsos motores e verbais. Elas consistem em uma agregação de processos cognitivos que permitem 0 homem a administrar os seus comportamentos e metas. Como também a avaliar a eficiência e a adequação delas, e do mesmo modo a abandonar as estratégias ineficazes em prol das mais eficientes e por fim, capaz de resolver os problemas imediatos e de médio e longo prazo (MALLOY-DINIZ et al., 2008, apud MALLOY-DINIZ et al., 2010).

Finalmente conceituaremos as disfunções executivas que foram analisadas através de pesquisas em pessoas que contêm comprometimentos que envolvem os circuitos pré-frontais que foram adquiridos no decorrer da vida, ou através de um desenvolvimento anormal ou por lesões (MALLOY-DINIS et al.; 2010; FLUENTES, 2014; ABREU e et al., 2010). Segundo Machado (2014) o circuito tem atribuições extremamente importantes nas chamadas funções executivas, elas englobam 0 planejamento e a execução das estratégias comportamentais mais adequadas, assim como tem a capacidade de alterá-las. Kandel (2014) descreve que as dificuldades das funções executivas podem estar ligadas ao TDAH, a qual, é caracterizada por falhas no controle inibitório abarcando uma menor flexibilidade, e por fim, possui dificuldade 
em delinear um planejamento. No entanto, as disfunções executivas dificultam o desempenho escolar e social por causa da incapacidade de planejar e desenvolver de tarefas que demandam atenção ao longo prazo.

$\mathrm{Na}$ fundamentação teórica pretendo conversar com estes autores citados e os demais nas referências bibliográficas deste trabalho para compreender TDAH e o funcionamento das funções executivas e com e a importância dela no desenvolvimento escolar da educação básica.

\subsection{TRANSTORNO DO TDAH}

TDAH é identificado por indicativos de impulsividade, de hiperatividade e desatenção que acarretam prejuízos nas relações sociais do portador incapacitando à realizações de tarefas com precisão e destreza. (VOIGT, 2018). Ao longo da história fora pesquisado com objetivo de compreender os comportamentos que saem da personificação cultural e social estabelecida e apresentar estratégias que possibilitem o portador do transtorno a desempenhar suas tarefas sociais e cognitivas com êxito.

O TDAH não é um problema atual, há relatos históricos de comportamentos estereotipados que eram observados em crianças. No século XVIII a obra "Uma investigação sobre a natureza e origem do desarranjo mental" do escocês Alexander Crichton de 1798 descreveu sintomas de inquietação mental e dificuldade dos meninos a prestarem atenção de maneira adequada. Estes sintomas encontram-se relacionados ao TDAH nas literaturas contemporâneas. No ano de 1845 o psiquiatra alemão Heinrich Hoffman compilou dez histórias descrevendo um grupo de crianças que apresentam patologias relacionadas a infância. Dentre estas histórias ele faz menção a de Philip the Nerve, o qual é classificado como um menino com problemas de atenção e deixa evidente também a sua intensa atividade através de sua obra "Der Struwwelpeter (Significado = "O menino desleixado". Entretanto, o crédito da publicação cientifica do TDAH foi para o médico e cofundador da Associação Britânica de Pediatria George Still. Ele em 1902 publica o artigo na revista Lancet, apresentando um grupo de crianças com sintomas semelhantes ao TDAH. Este artigo é considerado 
pelos os pesquisadores como a primeira publicação sobre o TDAH (BARKLEY, 2008; CALIMAN, 2010; MARTINEZ-BADÍA, 2015; DE VINUESA FERNÁNDEZ, 2017).

No século XX no ano de 1968 foi incluído o TDAH na literatura médica no DSM-2, foi classificado como a Reação Hipercinética da infância, era conhecida como a síndrome da criança hiperativa. Na edição seguinte do DSM-3 no ano de 1980 incluiu-se a termologia Transtorno do TDAH com ou sem hiperatividade. A edição posterior 1987 introduziu os termos TDAH ou distúrbio déficit de Atenção (DDA) no DSM-3-R, adotou somente estes dois subtipos. A partir de $1994 \mathrm{com}$ as novas atualizações do DSM-4 reconheceu que o TDAH poderia ser classificado em uma tríade: (1) predominante o desatento, (2) predominante hiperativo impulsivo e (3) predominante combinado (desatenção com hiperatividade e impulsividade). Esta classificação permaneceu na atualização do DSM-5 publicada em 2013 (DIAMOND, 2005; BARKLEY, 2008; ROTTA et al., 2008).

Na publicação da Classificação Internacional de Doenças (CID 10) define que os transtornos do comportamento e transtornos emocionais que se manifestam durante a infância ou na adolescência. O TDAH está relacionado no CID10 pela a classificação F90 como o transtorno hipercinético, são tipificados pela a falta de perseverança no cumprimento das tarefas, a desorganização, a impulsividade, por fim demostram dificuldades em cumprir as regras. Elas são intituladas por possui inibição social, déficit cognitivo e um atraso no desenvolvimento da linguagem e motricidade.

No DSM-5 "são apresentadas como excessiva (como uma criança que corre por tudo), inquieta (quando não apropriado ou remexer, batucar ou conversar em excesso). Nos adultos, a hiperatividade pode se manifestar como inquietude extrema ou esgotamento dos outros com sua atividade. A impulsividade refere-se a ações precipitadas que ocorrem no momento sem premeditação e com elevado potencial para dano à pessoa (por exemplo: atravessar uma rua sem olhar). A impulsividade pode ser reflexo de um desejo de recompensas imediatas ou de incapacidade de postergar a gratificação. Comportamentos impulsivos podem se manifestar com intromissão social (por exemplo, 
interromper os outros em excesso) e/ou tomada de decisões importantes sem considerações acerca das consequências de longo prazo (por exemplo: assumir um emprego sem informações adequadas)" (DSM-5, 2014, p.61).

A preponderância do TDAH é apontada pelo DSM- 5 com uma estimativa de $5 \%$ de crianças e $2 \%$ dos adultos são portadoras do TDAH. Os dados também apontam que o maior índice é entre os meninos chegando uma relação de 2 por 1 em relação ao gênero feminino. Entretanto, as meninas geralmente apresentam os sintomas de desatenção. O TDAH inicia-se na infância com os primeiros sintomas antes dos 12 anos e pode perdurar até a fase adulta, os sintomas se manifestam em casa, na escola e no trabalho (FUENTES et al., 2014).

As características associadas no DSM-5 para alicerçar o diagnóstico é a irritabilidades, a dificuldade de lidar com a frustração, a instabilidade de humor e a desatenção que estão associados ao mal desempenho das funções executivas. A tríade classificada pelo DSM-5 nos possibilita a compreender melhor as suas variações de sintomas e diferenciá-los em cada categoria. Barkley (2008) apresenta em sua obra os sintomas dos subtipos do TDAH que estão especificados:

1. Tipo predominante Desatento: apresenta dificuldades em fixar a atenção, não consegue terminar as tarefas, distraem com facilidade, necessita de supervisão para trabalhar, muda frequentemente de atividade sem que tenha terminado. Parece confuso e sonhando acordado, não conseguem cumprir adequadamente as regras, é desorganizado. Possui a hipoatividade, dificuldade de coordenação motora, déficit na memória de trabalho e dificuldade na execução das funções executivas (DIAS, 2009). Segundo Fuentes et al. (2014) às características do sujeito desatento abrange também a timidez e a passividade social. Este subtipo tende ser desleixados com seus pertences, esquecem itens relacionados a tarefas geralmente tendem a procrastinar o início de uma tarefa (DIAMOND, 2005).

2. Tipo predominante Hiperatividade-impulsividade: falta de inibição associada a hiperatividade, dificuldade para esperar para obter algo, hiperatividade e 
impulsividade, dificuldade em cumprir regras. São incapazes de terminar uma tarefa sem supervisão, inquietos, agitados. Caracterizam por falantes, desprovido de autocontrole, imaturos, autocentrados, irresponsáveis, preguiça e rudeza, desastrados. Possuem agitação nos pés e mãos, déficit de memória de trabalho e seletiva, e dificuldade na execução das funções executivas (DIAMOND, 2005).

3. Tipo predominante Combinado: é a junção dos sintomas do desatento e Hiperatividade-impulsividade, possui muita dificuldade em cumprir regras e obedecer a limites. É opositor, rude, insensível, dispersos e constituem dificuldades de socialização. Eles são caracterizados por hiperativos verbais e motores, são demasiadamente falantes e inquietos com movimentos repetitivos. São desorganizados e impacientes, costumam responder sem ouvir toda a pergunta e extremamente resistentes a regras e a rotina (DIAMOND, 2005).

O DSM-5 tipifica a gravidade da tríade equivalendo como a leve os casos onde os sintomas são poucos e trazem pequenos prejuízos nas esferas social, acadêmico e profissional. A moderada refere-se aos sintomas que se fazem presentes tanto na leve quanto na grave, porém os prejuízos são medianos. E a grave que corresponde os casos que apresentam muitos sintomas e podem a desenvolver diversos prejuízos nas esferas social, acadêmico e profissional.

\subsection{ASPECTOS NEUROBIOLÓGICOS DO TDAH}

O TDAH é um transtorno neurobiológico de concepção genética, concernente a disfunção na região pré-frontal do cérebro que é encarregado de controlar os impulsos, a inibir comportamentos, a gerenciar a atenção e memória como também a capacidade de planejar e organizar. Para a etiologia complexa do TDAH contribuem fatores genéticos e condições ambientais, suas bases neurobiológicas foram estabelecidas através de pesquisas que apontaram diversas anormalidades no sistema nervoso central de pacientes portadores dos transtornos (FUENTES et al., 2014). Através de estudos de famílias de gêmeos e adoção constataram a forte influências de fatores genéticos, os resultados dos estudos indicam a probabilidade 
de ocorrências do transtorno 2 a 8 vezes maior em parentes de crianças com a média estimada de $76 \%$ de herbidalidade. (FARONE et al., 2005 apud FUENTES et al., 2014).

Para a comunidade cientifica atual defende a existe de uma disfunção da neurotransmissão dopaminérgica no pré-frontal, frontal motora, giro cíngulo e nas regiões subcorticais no estriato, tálamo e médiodorsal e na região límbica no núcleo acumbens, amígdala e do hipocampo no TDAH. Estas disfunções estão centradas principalmente as insuficiências nos circuitos pré-frontal e amígdala no momento da neurotransmissão das catelominas resultando os sintomas de distração, impulsividade, esquecimento e desorganização (ROTTA et al., 2008; KANDEL, 2014; MACHADO, 2014).

Figura 1.

\section{O CÉREBRO DE QUEM TEM TDAH}

\begin{abstract}
As causas do TDAH ainda não estão completamente esclarecidas, mas a teoria corrente para explicá-lo associa o transtorno ao descontrole do córtex pré-frontal.

Essa região do cérebro é ligada ao raciocínio, ao controle emocional e à personalidade. Ela controla os impulsos e os pensamentos "de fundo" da mente para permitir que a pessoa foque. Em quem tem TDAH, esse "filtro" não funcio. naria muito bem, o que levaria a pessoa a ter dificuldade em controlar impulsos.
\end{abstract}

\section{SINTOMAS E SINAIS}

Adultos com TDAH podem:

- ter dificuldade para se planejar.

$\square$ falhar em cumprir prazos.

tender a começar uma atividade antes de terminar outra.

$\square$ ser desajeitados.
- ter dificuldade para esperar.

- mudar o comportamento quando é criticado.

- achar difícil seguir regras.

- fazer comentários inconvenientes sem controle.

\section{TRATAMENTO}

Em alguns casos, 0 adulto com TDAH desenvolve estratégias para lidar com os sintomas ao longo da vida, mas pode recorrer a tratamentos como:
- medicação, como os estimulantes metilfenidato (ritalina, por exemplo), lisdexanfetamina e alguns antidepressivos. nem sempre tão tomados diariamente.

Fonte: página o tempo.com.br[3]

Os aspectos neurobiológicos do TDAH decorrentes dos estudos de neuroimagem e de neurotransmissores que apontam 0 envolvimento das catecolaminas especificamente a dopamina e noradrenalina. O método neuromaturacional do encéfalo com o desenvolvimento bainha mielínica, a qual, a janela maturacional abre 
próximo do nascimento e fecha-se em torno de 2 anos. No ponto de vista neurobiológico é conveniente um grau apurado de hiperatividade em crianças sem lesões até aos 5 anos, considerando que a região pré-frontal só completa seu ciclo mielinogenético nesta faixa etária (ROHDE e HALPERN, 2004).

Também entre as ocorrências do TDAH há presença de fatores ambientais diversos verificadas em vários estudos realizados. Eles apontam que as crianças expostas a eventos pré-natais como exposição ao tabaco, álcool, drogas e toxinas ambientais, complicações na gestação ou no parto, prematuridade e baixo peso ao nascer. Também ocorre as interferências em eventos pós-natais precoces como anoxia neonatal, convulsões, lesão cerebral, exposição ao chumbo, bifenóis clorados. Podemos comtemplar também adversidade psicossociais e inconsistência na função parental. (ROHDE e HALPERN, 2004; FUENTES et al., 2014).

Segundo Jadidian (2015) o déficit das funções executivas do TDAH é prejudicado sendo atribuídos sintomas como a hiperatividade controle inibitório. Através de neuroimagens concluiu que o processamento límbico demonstra déficits em suas funções básicas como o tempo de respostas sendo especificamente demorada concluindo um atraso no desenvolvimento da maturação na área posterior do cérebro.

\section{AS FUNÇÕES EXECUTIVAS E SUA IMPORTÂNCIA NO DESENVOLVIMENTO ESCOLAR}

As funções executivas são primordiais para que o estudante obtenha sucesso em todas as etapas da educação. Contudo, é preciso levar em conta que elas se desenvolvem gradualmente ao longo da infância e adolescência (COSENZA e GUERRA, 2011). Para o TDAH o baixo desempenho escolar é um dos prejuízos funcionais frequente relacionados aos sintomas de desatenção que pode permanecer até a fase adulta. Os déficits de aprendizados compartilhados estão relacionados a problemas com a leitura, a escrita, a velocidade de processamento, problemas de atenção inibição e a memória operacional. Também possuem dificuldades com habilidades específicas como a consciência fonológica, o processamento numérico e de raciocínio geral e lógico (FUENTES et al., 2014). 
As funções executivas nos permitem a interação com o mundo frente os diferentes episódios que encontramos ao longo da vida. Através dela organizamos nosso pensamento considerando as experiências e os conhecimentos registrados na nossa memória, bem como as expectativas em relação ao futuro. Elas são espectadoras e executoras do nosso cotidiano, das tomadas de decisão, nas tarefas rotineiras e fazem parte dos planejamentos ao longo e curto prazo (COSENZA e GUERRA, 2011).

As funções executivas são constituídas por um conjunto de habilidades, que de forma integrada viabiliza o homem a gerenciar comportamentos, e a atingir metas propostas para resoluções de problemas e a conclusões de tarefas. Igualmente proporciona a avaliar a eficiência e a adequação destes comportamentos. Do mesmo modo nos possibilita a desabilitar as ineficazes estratégias em prol das mais eficientes (FUSTER, 2008; FUENTES et al., 2014). Também Eisenreich et al. (2017) afirma que a função executiva capacita o cérebro a regular o seu próprio processamento permitindo gerenciar as várias demandas celebrais sucessivamente. Desta forma é possível controlar a atenção, bloquear a memória de trabalho, codificar e recuperar a memória de longo prazo, do mesmo modo é capaz de simultaneamente manter e alterar o conjunto de tarefas. Permite assim a regular, a alterar as ações a promover a curiosidade de explorar novos conhecimentos. Tais ações, são indispensáveis no progresso de aprendizagem, já que elas fazem parte integrante da maneira de adquirir novos conhecimentos.

As funções executivas estão integradas as competências de planejamento e monitoramento, a memória de trabalho, o controle inibitório, a flexibilidade cognitiva e a atenção seletiva (DIAS, 2009). Estas funções permitem o homem interagir e se adaptar-se no meio que está inserido através da autoregulação, que oportuniza ações e metas dos processos mentais que estão associadas ao comportamento social e aos processos metacognitivos que incluem os aspectos da autoconsciência, da personalidade e da cognição social (CICERONE et al., 2006). 


\subsection{MEMÓRIA DE TRABALHO}

A memória de trabalho ao longo da história de sua conceitualização foi denominada como memória de curto prazo ou memória operaciona (KANDEL, 2014; FUSTER, 2008; ROTTA et al., 2008). Ela é apontada como parte integrante dos processos das funções executivas que contempla o gerenciamento das realizações das tarefas como a resolução de conflitos, a supressão de informação distratora, a realização de tarefas simultâneas e o monitoramento de erro e busca do sistema de memória. Estas tarefas requerem valências da atenção executiva (KANDEL 2000; DIAS, 2009). Sendo assim, a memória de trabalho é um sistema de capacidade limitada que permite a transição de informações processadas até o cumprimento da tarefa que a ser executada. Para este processamento da memória de trabalho o sistema possibilita uma série de operações mentais que constitui a elaboração e execução da tarefa. Para que isto seja possível, é realizada uma atualização continua através da interação e da integração da informação de conhecimentos provindo da memória de longo prazo juntamente com estímulos ambientais (MALLOY-DINIZ et al., 2008). A atuação da memória de trabalho permeia na compreensão, na aprendizagem e no raciocínio (DIAS, 2009).

Segundo Baddeley (2000), sua ação é integrada pelo sistema de controle da central executiva que se subdivide em alça fonológica e a prancha viso-espacial. Ela é responsável pelo processamento das atividades cognitivas e pelo controle da atenção. Podemos dizer que a memória de trabalho gerencia as informações recebidas e as codificadas nas demais memórias. O seu funcionamento da acontece de duas maneiras: (1) quando se trata de informações novas esta memória consegue armazenar e processar simultaneamente com apenas uma parcela de dados e só às mantêm no período que estão sendo utilizadas. (2) A outra maneira entra em ação quando a memória de trabalho precisa buscar informações anteriores que estão depositadas na memória de longo prazo. A memória de trabalho pode evocar uma quantidade enorme destas informações à medida que necessitar (BARKLEY, 2008; STERNBERG, 2010). 
O controle executivo central é estruturado por três subsistemas que são subordinados a central executiva que se beneficia de seus recursos para realizar as tarefas cognitivas. Para entender as subdivisões do sistema de controle da central executiva, se faz necessário definir suas áreas de atuação: a alça fonológica recebe e codifica as informações verbal e acústicas armazenando temporariamente. A prancha visoespacial ampara a informações visuais e espaciais que são associadas no hemisfério direito que contempla a área pré-motora, a áreas visuais secundárias, giro supramarginal e giro frontal inferior mutualmente (BADDELEY, 2000). Posteriormente Baddeley (2000) remodelou sua proposta original incluindo um quarto componente chamado "buffer episódico" que é responsável pelo o armazenamento temporário e limitado de informações provinda de diversas fontes fonológicas e viso-espaciais. Através de uma representação temporária e multimodal é feita uma analogia com back-up (DIAS, 2009). O buffer episódico possui três funções sendo a primeira (1) receber a informação temporal que é fundamental para registrar acontecimentos, também (2) fornece espaço para sustentar as informações recebidas da memória de longo prazo e sua última função é de (3) permitir a integração de informações visuais, fonológicas, espaciais (BADDELEY, 2000).

A área de atuação da memória de trabalho no cérebro é concentrada essencialmente no córtex pré-frontal, o córtex parietal, o córtex cingular anterior e partes do gânglio basal (KANDEL, 2006; STERNBERG, 2010; ROTTA et al., 2008). Podemos considerar que este componente das funções executivas é importante para aprendizagem humana, pois uma grande parte dela acontece no campo da memória de trabalho, porque ela é responsável por todas as informações recebidas em tempo presente (ROTTA et al., 2008).

\subsection{ATENÇÃO SELETIVA}

A atenção seletiva é o processamento mais relevante das informações, está envolvida no quesito foco, e desempenha o comportamento direcionado pelo controle inibitório (FUSTER, 2008). 
A atenção seletiva possibilita fazer uma triagem e direcionar o estímulo que irá focalizar a atenção e ignorar outros estímulos que estão disponíveis no momento e são irrelevantes (GAZZANINGA, 2006). Compreende-se que a filtragem de informação realizada pela atenção seletiva é um mecanismo facilitador das respostas neurais na concentração e a realização da tarefa que precisa ser executada nos processos mentais deixando outros estímulos em um segundo plano (LENT, 2008).

Segundo Dias (2009) a atenção pode ter distintas orientações apresentadas nas literaturas como voluntária e automática. A atenção voluntária relaciona-se aos processos acessíveis e dependente do controle consciente que abrange o controle descendente top-down. A atenção automática tem um envolvimento menor grau exigindo pouco ou nenhum esforço na realização da tarefa, ela tem o controle ascendente bottom-up (GAZZANINGA, 2006). Esta atenção seletiva está presente em todas as ações voluntárias ou involuntárias tornando parte integrante na codificação de informações e realizações de tarefas, sendo ela um integrante importante no processo das funções executivas. É através delas que a leitura é codificada dos recursos atencionais, e passa pelo processo de filtragem para identificar o estímulo que necessita os esforços da atenção e execução propriamente dito (STERNBERG, 2010).

Para que a atenção seletiva opere corretamente ela precisa do apoio da atenção sustentada que a capacita manter o foco por um período prolongado. $\mathrm{O}$ foco consciente ao estímulo específico, este aspecto é denominado de concentração ou vigilância. (LENT, 2008). As funções executivas atuam como naipes de uma orquestra que produzem uma linda sinfonia (BARKLEY, 2009).

\subsection{CONTROLE INIBITÓRIO}

O controle inibitório constitui na capacidade de inibir respostas e reações a estímulos distratores que prejudique o curso correto de uma ação (FUENTES et al., 2014). Também é responsável por coibir e conter intencionalmente alguns estímulos dominantes ou automáticos através de um mecanismo de filtragem integrada a atenção seletiva (GAZZANINGA, 2016). Estes estímulos podem ser de natureza 
cognitiva ou comportamental (Gil, 2006), que possibilitam o gerenciamento das tarefas diárias que têm a incumbência de inibir uma ação que está em andamento e recomeçar outra ação. Fuster (2008) conceitua o controle inibitório como componente destinado a processar sensoriais, motoras e outras e suprimir ao foco necessária da atenção filtrando as informações importantes para o momento. Com esta habilidade permite a gerenciar os impulsos automáticos e dominantes viabilizando alternar entre as tarefas (DIAS, 2009).

\subsection{FLEXIBILIDADE COGNITIVA}

A flexibilidade cognitiva é a capacidade do nosso cérebro de alternar e mudar o curso das ações que experenciamos durante ao longo da vida, que possibilita nos adaptarmos com novas experiências cognitivas (FUENTES et al., 2014). Segundo Dias (2009), a flexibilidade ela atua entre a atenção alternada e atenção dividida que interagem no processo da informação permitindo o comprometimento do homem com a execução da tarefa e o processamento dela. A flexibilidade cognitiva refere-se à competência que o homem tem para organizar elementos em categorias, como também de substituir o curso das ações ou pensamentos de acordo com as demandas do ambiente (MALLOY-DINIZ et al., 2010).

A flexibilidade cognitiva baseia-se no controle inibitório, ela engloba a ser flexível e ajustar as demandas ou prioridades, também é capaz de admitir o erro e mudar o curso de decisões tomadas (DIAMOND, 2013).

\subsection{PLANEJAMENTO E MONITORAMENTO, RACIOCÍNIO E SOLUÇÕES DE PROBLEMAS, METACOGNIÇÃO}

O planejamento segundo Fuentes et al. (2014) representa a competência de estabelecer a melhor maneira de atingir uma meta levando em conta a hierarquização dos passos e a aplicação de instrumentos necessários para execução dos objetivos. O raciocino é a habilidade de planejamento e execução de ações para a resolução de problemas diários ao longo da vida. Eles poder ser esquematizados através de uma tríade que possibilite em primeiramente identificar os objetivos demarcando por grau 
de prioridades, próximo passo é avaliar as consequências das alternativas que optou e finalizando a tríade estabelecer os passos imprescindíveis para alcançar seus objetivos propostos. (MALLOY-DINIZ et al., 2010; FUENTES et al., 2014). Dentro desta perspectiva colocada por Malloy-Diniz (2010) e colaboradores apontam o planejamento é elemento central para solucionar problemas que abrange tarefas rotineiras como também aquelas novas que exigem soluções inéditas no processo diário cognitivo.

Para Fuster (2008) o planejamento é a execução de ações direcionadas com objetivos propostos e guiados por estratégias formuladas para alcançar uma meta. As literaturas apresentam que o planejamento adequado habilita o homem a credenciar e requalificar as mudanças circunstanciais e apresentar opções diante as demandas dos problemas através da flexibilidade cognitiva e a memória de trabalho (LEZAK et al., 2004 apud DIAIS, 2009).

Outro componente da metacognição é o monitoramento tem como objetivo central a autoregulação que capacita o processamento das informações e identificar situações de conflito ou erros na execução de tarefas. (GAZZANINGA, 2006). Segundo Fuster (2008) o monitoramento tem a função de medir os efeitos das nossas ações e analisar nossos objetivos e expectativas, também corrigir nossas ações, sendo uma espécie de feedback.

Dias (2009) aponta que o monitoramento estabelece relação e influência com a flexibilidade cognitiva que é integrante indispensável para auto regulação e auto reflexão que se faz necessária para o desenvolvimento da monitoração.

A Metacognição integra as celebrais responsáveis pelas habilidades ao automonitoramento cognitivo sendo capaz de traçar o planejamento, o monitoramento da ação para aprender e refletir sobre seus sucessos e insucessos no processo de aprendizagem (CICERONE et al., 2006). 


\subsection{ASPECTOS NEUROBIOLÓGICOS DAS FUNÇÕES EXECUTIVAS}

De acordo com as literaturas as funções executivas são mediadas pelo lobo frontal que é uma espécie de diretor executivo do funcionamento das atividades mentais humana. No entanto, o gerenciamento envolve diferentes sistemas de neurotransmissão, assim sendo que as alterações neste sistema também estão ligadas ao desempenho das funções executivas. Exemplificando, as vias dopaminérgicas estão correlacionadas a memória operacional, controle inibitório, atenção, planejamento, flexibilidade cognitiva, tomada de decisão. As alterações na neurotransmissão dopaminérgica danificam as funções mencionadas conforme podemos detectar em transtornos como o TDAH (FUENTES et al., 2014).

O circuito pré-frontal dorsolateral é associado a funções executivas como na organização das respostas comportamentais a problemas complexos e no uso de habilidades verbais para a solução de problemas (KANDEL, 2014). É certo que as funções executivas predominam no córtex frontal é representado por córticossubcorticais que emanam setores delimitados do córtex frontal. São delimitados cinco circuitos (1) motor, (2) oculomotor, (3) cíngulo anterior, (4) frontal dorsolateral e (5) orbitolateral. Destes cincos circuitos apenas três estão relacionados ao desempenho das funções executivas que são: (1) dorsolateral, (2) orbitofrontal e (3) cíngulo anterior (FUENTES et al., 2014). Estes componentes integram papeis que atuam nas funções da agilidade comportamental, controle voluntário sobre os movimentos oculares, a flexibilidade cognitiva, iniciativa e espontaneidade comportamental através da motivação e impulso e adequação do comportamento ao ambiente social (LENT, 2008). 


\section{7 ÁREAS RESPONSÁVEIS PELAS FUNÇÕES EXECUTIVAS}

Figura 2.

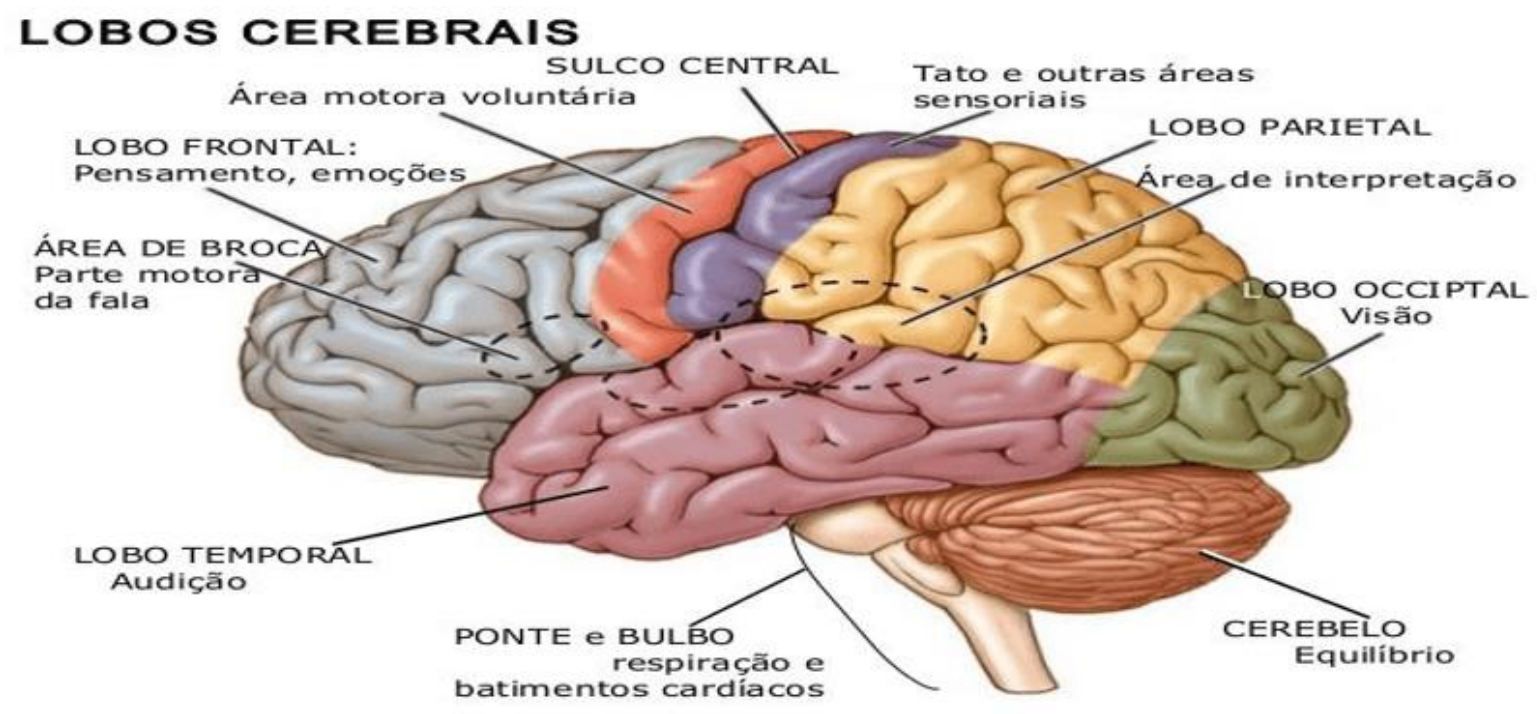

Fonte página pinterest.com[4]

A área pré-frontal possui conexões com quase todas as áreas corticais, vários núcleos talâmicos principalmente o núcleo dorsomedial, amígdala, hipocampo, núcleos de base, cerebelo, tronco encefálico suas conexões abrange quase todo o encéfalo. Através destas vastas conexões permite exercer coordenadas funções neurais sendo o principal responsável pelo nosso comportamento inteligente (MACHADO, 2014)

De acordo com Fuentes et al. (2014), o circuito dorsolateral está relacionado a processos cognitivos que envolvem estabelecimento de metas, planejamentos, soluções de problemas, categorização, memórias operacional, monitoração da aprendizagem e da atenção, flexibilidade cognitiva, capacidade de abstração, autoregulação, julgamento, tomada de decisão, foco e sustentação da atenção. A área de atuação do circuito orbitofrontal é o processamento cognitivo emocional, estando associado a aspectos do comportamento social como a empatia, o cumprimento de regras sociais, o controle inibitório e a automonitoração. Já o circuito do cíngulo anterior é importante para a motivação, a monitoração de comportamento, o controle executivo da atenção e a seleção e controle de respostas. 
Para Fuentes et al. (2014), alguns teóricos dividem as funções executivas em dois domínios gerais: (1) Frio (cool), mais abstrato-cognitivo que incluem a inibições de respostas motoras, atenção, flexibilidade cognitiva. (2) Quente (hot) que envolve o processamento de recompensas que incluem incentivo e a motivação que engloba a tomada de decisão afetiva ou impulsiva.

\section{DISFUNÇÕES EXECUTIVAS NO PROCESSO ENSINO APRENDIZADO DO TDAH}

O aperfeiçoamento das funções executivas é um marco adaptativo significativo para o homem, ela está relacionada com a competência de imitar e aprender com a observação do comportamento do outro. É certo que as funções executivas trazem equilíbrio para o desenvolvimento cognitivo e social, e alterações nelas, as chamadas disfunções executivas trazem o desequilíbrio e acarretam níveis de gravidade para o TDAH à medida que apresentem sintomas de dificuldade de reorganização dos sistemas neurais compensatórios e a capacidade de lidar com adversidades em situações cotidianas (FUENTES et al., 2014).

As distinções entre as funções e disfunções da atenção do TDAH refere-se ao uma importante distinção médica, ética e moral que está relacionada entre o funcionamento patológico da atenção e do autocontrole que delimitam o diagnóstico do TDAH sendo ele heterogêneo e frágil, se tornando um desafio para os profissionais da saúde envolvidos (CALIMAN et al., 2008).

As disfunções executivas correspondem a alterações nas funções cognitivas e comportamentais diversas correlacionadas ao comprometimento de seus processos que se catalogam como a dificuldade na seleção de informação, a distração, a dificuldade da tomada de decisão, problemas com a organização, dificuldade com a aquisição de novos repertórios e com a abstração, bem como gerenciar os impulsos apresenta dificuldade em controlar e gerenciar deu comportamento com antecipação causando problemas na vida diária (DIAS, 2009). Tais comportamentos geram o imediatismo ocasionando limitações nas habilidades do planejamento, memória evocativa e na linguagem expressiva (LENT 2008). 
Barkley (2008), menciona que o TDAH expressa uma alteração no funcionamento executivo especialmente na capacidade de inibir o comportamento repercutindo sobre o autocontrole. Os pacientes com lesões pré-frontais podem acarretar vários problemas que caracterizam as chamadas "disfunções executivas". Alguns pacientes podem apresentem um nível de inteligência inalterado, serem incapazes de tomar decisões necessárias no dia a dia, ou tomar decisões desastrada e com dificuldade de avaliar as prioridades, consequências ou riscos aos envolvidos. Além de não conseguirem perceber e avaliar seus próprios erros. Outros podem ser impulsivos e incapazes de inibir comportamentos inadequados ou de flexibilizar sua conduta, mesmo constando que suas ações não levam ao objetivo determinado (COSENZA e GUERRA, 2011).

A disfunção executiva é a dificuldade que o ser possui para realizar tarefas cotidianas de maneira autônoma. Umas das principais características são a lentidão psicomotora, a perda rápida do reflexo vestibular ocular a comportamentos antissociais. (LENT, 2008). Estes déficits das funções executivas envolvem os circuitos pré-frontais que resulta a comprometimentos cognitivos como estabelecimento de metas, planejamentos e soluções de problemas, memória operacional, monitoração de aprendizagem, flexibilidade cognitiva, abstração e julgamento. e comportamentais como apatia, desmotivação, dificuldades de controle atencional e desinibição de respostas instintivas. Os quadros que procedem de lesões que abrangem os circuitos pré-frontais orbitofrontais são classificados são abalizados por alterações abruptas de personalidade e apresenta dificuldades para inibir comportamentos impróprios e imediatistas, tomar decisões e considerar consequências ao longo prazo (MALLOY-DINIZ et al., 2010).

Os aspectos neuropsicológicos fundamentais do TDAH são relacionados aos problemas das funções executivas que abrange os controles executivos e cognitivos que se referem a tarefas do cotidiano que exigem concentração e esforço deliberado. Tais execuções de tarefas são importantes para diversos aspectos da vida como saúde, qualidade de vida, potencial para aprendizagem, realização profissional e sucesso escolar (DIAMOND, 2013). 
A função executiva é ampla e abrange quatro domínios (1) cognitivo executivo, (2) autoregulação, (3) comportamental, (4) metacognitivo. Estes quatros domínios podem apresentar disfunções executivas levando ao comprometimento funcionais executivas que necessitem de uma reabilitação holística direcionada e interversões terapêuticas que se apropriem de múltiplas abordagens com objetivo de elucidar os mecanismos utilizados para as intervenções as funções executivas (CICERONE et al., 2006).

\section{AS INTERVERSÕES ESCOLARES PARA TDAH}

Os estudos apontam que o TDAH possui dificuldades no desenvolvimento acadêmico, entretanto ele pode adquirir sucesso acadêmico. As dificuldades apontadas na função motora fina podem dificultar o desempenho escolar comprometendo a escrita podendo desenvolver disgrafia (BARKLEY, 2008). Segundo Rohde (2004) o TDAH está associado ao baixo desempenho escolar, repetências e relações difíceis com colegas. Presume que o TDAH pode ocasionar baixo rendimento escolar, repetência, expulsão e baixo e desinteresse pela escola devido a dificuldade em desenvolver as habilidades de leitura, escrita e desempenho matemático com êxito. Pesquisadores também pontuam que há variáveis em fatores ambientais e individuais, portanto nos estudos é constatado que o TDAH possui notas baixas em relação aos outros alunos (SCHMITT, 2017).

A partir das evidências cientificas de que cada cérebro é único e tem sua particularidade que o distingui dos demais, o professor tem a função de conhecer cada aluno e encara-lo como um ser único. Também compactua com os conhecimentos da neuroeducação para auxiliar neste conhecimento e compreender como o aluno aprende, também observa seu comportamento dentro e fora da sala de aula, a sua estrutura familiar, a alimentação e se dorme devidamente que são tópicos fundamentais desenvolvimento cognitivo. É importante compreendermos que fatores externos influenciam positivamente ou negativamente o processo de aprendizagem. Segundo pesquisas apontam que alunos em condições socioeconômicas podem sofrer apresentar problemas com a nutrição e com horas inadequadas de sono prejudicando o desenvolvimento cognitivo (ALMEIDA, 2019). 
De acordo com Cosenza e Guerra (2011), as funções executivas estão se desenvolvendo progressivamente entre a infância e a adolescência e são de fundamentais o sucesso do estudante em todas as etapas de sua educação. Seu desenvolvimento progressivo caracteriza por meio dos estágios classificados por alguns autores no desenvolvimento do homem. É descrito pelos processos iniciando pelos primeiros meses de vida os bebês são expostos a estímulos imediatos e apenas respondem a eles. Nos dois primeiros anos começam aperfeiçoar sua capacidade atencional e já ignoram estímulos irrelevantes. A partir dos três anos, ela passa ter noção do passado e futuro, possui a capacidade de planejamento e de flexibilidade de estratégias, que estará bem aperfeiçoado em torno dos sete anos de vida. $\mathrm{O}$ desenvolvimento do córtex pré-frontal que acontecem do nascimento aos 2 anos a primeira fase, dos 7 ao 9 a segunda fase e entre os 16 aos 19 a terceira fase, elas podem ser influenciadas pelos fatores ambientais que trará um desenvolvimento individual. Cada pessoa ao longo da vida adquirirá habilidades distintas de acordo com os estímulos e experiências que ela foi exposta no período do seu crescimento.

O professor pode se apropriar dos conhecimentos da neurociência para tornar a aprendizagem mais significativa promovendo experiencias educacionais enriquecedoras para o aluno aos alunos despertando a atenção e o interesse aos novos conhecimentos. (ALMEIDA, 2019).

Para Barkley (2008), o sucesso educacional do portador do TDAH envolve uma tecnologia comportamental documentada e a presença de professores envolvidos no processo de ensino dos alunos portadores do TDAH. Verifica-se que um relacionamento construtivo entre professor e aluno se baseia na compreensão que o professor possui referente ao aluno portador do TDAH. Barkley (2008) pontua que os professores necessitam estar cientes dos seguintes pontos: (1) o TDAH é considerável uma deficiência educacional de base biológica tratável mas não curável; (2) o TDAH não se deve a falta de habilidade ou conhecimento, mas na dificuldade de manter a atenção, o esforço e a motivação e a inibir comportamento ao longo do tempo; (3) para estudantes portadores do TDAH é mais difícil fazer o mesmo trabalho acadêmico e apresentar o comportamento social esperado dos outros estudantes; (4) 
as interversões mais efetivas para melhorar o desempenho escolar são aplicadas de forma coerente dentro do ambiente escolar; (5) as interversões escolares têm de ter estratégias proativas e reativas para maximizar a mudança de comportamento; (6) os professores necessitam considerar o uso dos colegas, pais ou computadores para administrar interversões em sala de aula.

Outro ponto importante a ser considerado é a relação entre o lar e a escola que beneficia o desenvolvimento acadêmico. Através da clareza e entendimento dos sintomas e dificuldades do TDAH no processo de aquisição de conhecimento, os pais e a escola e sua equipe de profissionais necessitam deixar de lado os conflitos de culpa e responsabilidade, e, ambos prosseguir com estratégias educacionais e comportamentais que possam possibilitar e facilitar o ensino do portador do TDAH. Estas estratégias podem ser orientadas e supervisionadas através de profissionais da área da saúde e auxílios terapêuticos e quando necessário farmacológico (BARKLEY, 2008).

No prisma das diretrizes comportamentais gerais a abordagem é diferenciada através do nível diagnostico e o subtipo que o portador apresenta. O portador com o tipo predominante desatento apresenta o processo cognitivo lento, com baixos níveis de curiosidade e interesse pela aprendizagem. Tem preferência por tarefas com menor grau de dificuldade, ele tem simpatia pelo trabalho cooperativo a apresenta um bom desenvolvimento em trabalhos não competitivos. Podem ter um mal comportamento quando expostas a companhias com comportamento antissocial. Já o portador do tipo predominante Hiperatividade-impulsividade pode se favorecer de interversões comportamentais e medicações estimulantes quando necessárias. E por fim, o portador do tipo predominante combinado pode ser amparado através de uma combinação de medicações e interversões comportamentais (BARKLEY, 2008).

As abordagens comportamentais são descritas em três argumentos que compõe ações necessárias. O primeiro é concentrar no ensino às crianças de um conjunto de habilidades e comportamentos adaptativos para substituir os problemáticos. Exemplificando na área organizacional treinar a criança a guardar seus pertences na bolsa corretamente. $\mathrm{Na}$ área comportamental treinar as crianças a substituir um 
comportamento agressivo por outro. Em segundo ponto incluir o desempenho acadêmico pesquisas indicam que a melhora do comportamento traz uma melhora no desempenho acadêmico, pois o comportamento adequado proporciona uma capacidade melhor a atenção e desenvolvimento das habilidades de leitura, escrita e ortografia. E o terceiro ponto apresentado é incluir situações problemáticas comuns como transições de classe e atividades, intervalo e lanches (BARKLEY, 2008).

Para Barkley (2008) as interversões comportamentais do TDAH englobam diversas modificações na sala de aula como o espaço físico, tarefas acadêmicas e treinamento para os pais para o controle infantil do comportamento em casa. Ele pontua oito passos para estas interversões: (1) informar regras e instruções de forma clara e objetiva; (2) as consequências utilizadas para controlar o comportamento devem ser utilizadas de forma imediata; (3) as consequências do seu comportamento devem ocorrer frequentemente e informadas qual regra fora quebrada; (4) os tipos de consequências deve ações necessárias para inibir o comportamento seguida de motivação ao comportamento correto. (5) antes a da punição deve ter antes a motivação ao comportamento correto; (6) as gratificações ou reforços ao bom comportamento deve ser alternadas frequentemente; (7) a utilizar a previsão se beneficiando de planejamento regras e consequências para s a coordenar as ações tomadas em sala de aula; (8) As crianças portadoras do TDAH necessitam ser responsabilizadas em público por seu mal comportamento e também ser elogiadas e gratificadas publicamente pelo cumprimento dos seus objetivos e (9) as interversões comportamentais são bem sucedidas se forem acompanhadas com gestos de afetividade e interação demonstrados ao aluno portador de TDAH.

A estrutura da sala de aula, a demanda do trabalho e adaptações curriculares também precisam ser pensados para contribuir para o sucesso escolar do TDAH. A sala de aula deve ser arrumada de maneira que possibilite a monitoração do comportamento do aluno de maneira mais efetiva, é importante também a organização da estrutura e rotina com apoio visuais recomendáveis como tabelas e regras com visual atraente. Já no quesito tarefas escolares precisam ser (1) compatíveis as habilidades cognitivas; (2) apresentar variação de formatos com níveis de dificuldades 
intercaladas; (3) necessitam se breves e adaptáveis ao tempo de atenção das crianças; (4) expor as lições com motivação e permitindo a participação ativa das crianças; (5) intercalar aulas expositivas com dinâmicas que auxiliem a retomada da atenção; (6) aplicar as disciplinas acadêmicas nas primeiras horas do período escolar, procurando deixar as atividades mais ativas para serem aplicadas posterior. (7) adaptar trabalhos escritos para o uso de computadores trazem benefícios positivos; (8) estudam comprovam que proporcionar opções de trabalho para o estudante de TDAH pode promover resultado positivo a produtividade. O computador pode ser utilizado como uma ferramenta auxiliar ao processo de ensino e aprendizagem, sendo utilizado por meio de software de pesquisas, jogos relacionados a disciplina ou para realizar relatórios compostos de gráficos e visuais que facilitam a compreensão da disciplina. E por fim, a adaptação do currículo seja necessário basicamente nas áreas da leitura, escrita, ortografia e matemática apresentando estratégias que viabilizem a internalização cognitiva das disciplinas através de terapias educacionais (BARKLEY, 2008).

Pode se classificar a tarefa de casa como uma estratégia eficaz. O departamento de Educação dos Estados Unidos realizou um estudo de cinco meses com 222 estudantes do ensino médio portadores de TDAH e contou com apoio e reunião com os pais e professores visando a verificar a interversão da lição de casa. Concluiu que as lições de casa produzem respostas positivas proporcionando o treinamento de habilidades como organização, planejamento e concentração, resolução de problemas e conclusão de tarefas. Alunos que pontuaram abaixo da média acadêmica conseguiram melhorar sua pontuação nas quesito leitura e matemática (BREAUX et al., 2018).

\section{CONSIDERAÇÕES}

"O córtex cerebral", diz ele sobre a camada fina e mais externa do cérebro, "refina seletivamente suas capacidades de processamento para se adaptar a cada tarefa." Isto não é simplesmente aprender; sempre é "aprender a aprender". O cérebro que Merzenich descreve não é um recipiente inanimado que preenchemos; na realidade, parece mais uma 
criatura viva dotada de apetite, uma criatura que pode crescer e se transformar com nutrição e exercícios adequados. (NORMAN, 2016)

Esta pesquisa coadjuva a compreensão dos sintomas e dificuldades que ० TDAH compactua nas esferas sociais e cognitivas. A tríade apresentada constituída segundo o DMS-5 (1) tipo predominante desatento, (2) tipo predominante hiperativo-impulsivo e (3) tipo predominante combinado. É classificada segundo suas particularidades e estratégias de interversão no campo escolar. Assim como salientamos a importância de interversões terapêuticas e farmacológicas quando necessárias para uma melhor qualidade de vida e desempenho escolar e profissional. Igualmente é mencionado que um dos principais indicadores do TDAH é a disfunção executiva, que leva o portador a apresentar comprometimentos nas realizações de tarefas e de tomada de decisão.

É importante reedificar que Barkley (2008) pontua que o sucesso educacional do portador do TDAH envolve uma tecnologia comportamental documentada e a presença de professores envolvidos no processo de ensino dos alunos portadores do TDAH. O relacionamento construtivo entre professor e aluno se baseia na compreensão que o professor possui referente ao aluno ao TDAH. As interversões mais efetivas podem melhorar o desempenho escolar e as interversões escolares têm de ter estratégias proativas e reativas para maximizar a mudança de comportamento e o por fim, o professor necessita considerar o uso dos colegas, pais ou computadores para administrar interversões em sala de aula.

Segundo Diamond (2013) as funções executivas nos permitem a brincar com as ideias podendo ao mesmo tempo gerenciar ações e pensamentos. Resolver imprevistos resistir tentações, agir de maneira criativa e focar naquilo que é importante. Nos permite a gerenciar nosso aprendizado e traçar nosso comportamento e por fim, coordenar meu dia a dia. Elas formam um conjunto de capacidades que nos permitem a executar as ações necessárias para programar e atingir um objetivo concluir tarefas (COSENZA e GUERRA, 2011). Nesta conjuntura, as funções executivas compõem um mecanismo de controle cognitivo que direciona e coordena o comportamento humano de maneira adaptativa, possibilitando mudanças rápidas e flexíveis diante de novas exigências do ambiente (ALMEIDA, 2019). São compostas pela a memória de 
trabalho, a atenção seletiva, o controle inibitório, o planejamento, o monitoramento e a flexibilidade cognitiva. Estas habilidades envolvem a regulação comportamental e colaboram para os processos cognitivos e adaptativos mediante as novas experiências (DIAS, 2009).

De acordo com Cosenza e Guerra (2011), as funções executivas estão se desenvolvendo progressivamente entre a infância e a adolescência e são de fundamentais o sucesso do estudante em todas as etapas educacionais. Por esta razão é aconselhável o professor se apropriar dos conhecimentos da neurociência para tornar a aprendizagem mais significativa promovendo experiências educacionais enriquecedoras para o aluno aos alunos e despertando a atenção e o interesse aos novos conhecimentos. (ALMEIDA, 2019).

No término desta pesquisa bibliográfica é importante elucidar a notória precisão em se aprofundar em novos estudos proporcionem estratégias e práticas pedagógicas e comportamentais que auxilie o desenvolvimento cognitivo e social do TDAH e que proporcione a melhor execução e treino das funções executivas.

\section{REFERÊNCIAS}

ALMEIDA, Ana Catarina Moreira de. Neuroeducação e flexibilidade curricular: Definição de estratégias e modos de trabalho pedagógico. 2019. Tese de Doutorado. Acesso: 28/08/2019 http://repositorio.esepf.pt/handle/20.500.11796/2772

AMERICAN PSYCHIATRIC ASSOCIATION et al. DSM-5: Manual diagnóstico e estatístico de transtornos mentais. Artmed Editora, 2014.

BEAR, Mark F.; CONNORS, Barry W.; PARADISO, Michael A. Neurociências: desvendando o sistema nervoso. Artmed Editora, 2008.

BADDELEY, Alan. The episodic buffer: a new component of working memory?. Trends in cognitive sciences, v. 4, n. 11, p. 417-423, 2000. Acesso: 14/10/2019 https://www.cell.com/action/showPdf?pii=S1364-6613\%2800\%2901538-2 
BARKLEY, Russell A. Transtorno de déficit de atenção/hiperatividade: manual para diagnóstico e tratamento. Artmed Editora, 2008.

BREAUX, Rosanna P. et al. Brief homework intervention for adolescents with ADHD: Trajectories and predictors of response. School Psychology Quarterly, 2018.

CALIMAN, Luciana Vieira. O TDAH: entre as funções, disfunções e otimização da atenção. Psicologia em estudo, v. 13, n. 3, p. 559-566, 2008. Acesso: 28/08/2019 https://www.redalyc.org/pdf/2871/287122110017.pdf

CALIMAN, Luciana Vieira. Notas sobre a história oficial do transtorno do TDAH TDAH. Psicologia: ciência e profissão, v. 30, n. 1, p. 46-61, 2010. Acesso: 28/08/2019 http://www.scielo.br/pdf/pcp/v30n1/v30n1a05

CARMARGOS, W.; HOUNIE, A. G. Manual clínico do transtorno de déficit de atenção/hiperatividade. Editora Info Ltda. Belo Horizonte, 2005.

CICERONE, Keith et al. Cognitive rehabilitation interventions for executive function: moving from bench to bedside in patients with traumatic brain injury. Journal of cognitive neuroscience, v. 18, n. 7, p. 1212-1222, 2006. Acesso: 22/10/2019 https://www.mitpressjournals.org/doi/abs/10.1162/jocn.2006.18.7.1212

COSENZA, Ramon; GUERRA, Leonor. Neurociência e educação. Artmed Editora, 2011.

DIAS, Natália Dias et al. Avaliação neuropsicológica das funções executivas: Tendências desenvolvimentais e evidências de validade de instrumentos. 2009. Acesso: 28/08/2019. http://tede.mackenzie.br/jspui/handle/tede/1746

DIAMOND, Adele. Attention-deficit disorder (attention-deficit/hyperactivity disorder without hyperactivity): A neurobiologically and behaviorally distinct disorder from attention-deficit/hyperactivity disorder (with hyperactivity). Development and psychopathology, v. 17, n. 3, p. 807-825, 2005. Acesso: 12/11/2019 https://doi.org/10.1017/S0954579405050388 
DIAMOND, Adele. Executive functions. Annual review of psychology, v. 64, p. 135168 2013.

Acesso:

$12 / 11 / 2019$

https://www.ncbi.nlm.nih.gov/pmc/articles/PMC4084861/

DIAMOND, ADELE. Why improving and assessing executive functions early in life is critical. Executive function in preschool-age children: Integrating measurement, neurodevelopment, and translational research, p. 11-43, 2016. Acesso: $12 / 11 / 2019$

http://www.devcogneuro.com/Publications/Diamond_(2016)_Why_improving_and_as sessing_executive_functions.pdf

DE VINUESA FERNÁNDEZ, Fernando García. Prehistoria del TDAH: Aditivos para un diagnóstico insostenible. Papeles del Psicólogo, v. 38, n. 2, p. 107-115, 2017. Acesso:

08/09/2019 https://www.researchgate.net/profile/Fernando_Garcia_De_Vinuesa/publ ication/314193432_Prehistoria_del_TDAH_Aditivos_para_un_diagnostico_insostenib le/links/594a32fda6fdcc3e17ff4ecd/Prehistoria-del-TDAH-Aditivos-para-undiagnostico-insostenible.pdf

EISENREICH, Benjamin R.; AKAISHI, Rei; HAYDEN, Benjamin Y. Control without controllers: toward a distributed neuroscience of executive control. Journal of cognitive neuroscience, v. 29, n. 10, p. 1684-1698, 2017. Acesso: 22/10/2019 https://www.biorxiv.org/content/biorxiv/early/2016/09/26/077685.full.pdf

FUENTES, Daniel et al. Neuropsicologia-: Teoria e Prática. Artmed Editora, 2014.

Fuster, J. M. (2008). The Prefrontal Cortex: Anatomy, physiology, and neuropsychology of the frontal lobe (4 ed.): Lippincott, Williams \& Wilkins citação da 4 edição vereficar FUSTER, Joaquin. The prefrontal cortex. Academic Press, 2015.

GAZZANIGA, M.S.; IVRY, R.B.; MANGUN, G.R. Neurociência Cognitiva: A biologia da Mente. Porto Alegre: Artmed, 2006

GIL, Roger. Manual Neuropsicología. Paris, Masson, 2006 
JADIDIAN, Alex; HURLEY, Robin A.; TABER, Katherine H. Neurobiology of adult ADHD: Emerging evidence for network dysfunctions. The Journal of neuropsychiatry and clinical neurosciences, v. 27, n. 3, p. 173-178, 2015. Acesso:13/10/2017 https://neuro.psychiatryonline.org/doi/full/10.1176/appi.neuropsych.15060142

KANDEL, Eric et al. Princípios de Neurociências-5. AMGH Editora, 2014..

LENT, R. Cem bilhões de neurônios. Rio de Janeiro: Atheneu, 2008.

MACHADO, Ângelo B. M. Neuroanatomia funcional. Atheneu, 2014.

MALLOY-DINIZ et al. Neuropsicologia das Funções Executivas. In: FUENTES, D. et al. (2008). Neuropsicologia: teoria e prática. Por Alegre: Artmed, 2008

MALLOY-DINIZ, L. F.; FUENTES, D.; MATTOS, P. Abreu. N (org.).. Avaliação Neuropsicológica. Artimed, 2010

MARTINEZ-BADÍA, Jose; MARTINEZ-RAGA, Jose. Who says this is a modern disorder? The early history of attention deficit hyperactivity disorder. World journal of psychiatry, v. $5, \quad$ n. 4 , p. 379,2015 . Acesso em 08/09/2019: https://www.ncbi.nlm.nih.gov/pmc/articles/PMC4694551/

ROHDE, Luis A.; HALPERN, Ricardo. Transtorno de déficit de atenção/hiperatividade: atualização. Jornal de Pediatria, v. 80, n. 2, p. 61-70, 2004. Acesso: 05/11/2019 http://www.scielo.br/pdf/\%0D/jped/v80n2s0/v80n2Sa08.pdf

ROTTA, Newra Tellechea; OHLWEILER, Lygia; DOS SANTOS RIESGO, Rudimar. Transtornos da aprendizagem: abordagem neurobiológica e multidisciplinar. Artmed Editora, 2008.

SCHMITT, Juliana Campos; MORANDO, Eunice Maria Godinho. TDAH e desempenho acadêmico: uma descrição do conhecimento atual. International Journal of Developmental and Educational Psychology. Revista INFAD de Psicología., v. 2, n. 2, p. 279-288, 2018. 
VOIGT, Robert G. et al. Academic achievement in adults with a history of childhood attention-deficit/hyperactivity disorder: a population-based prospective study. Journal of developmental and behavioral pediatrics: JDBP, v. 38, n. 1, p. 1, 2017. Acesso em 08/09/2019: https://www.ncbi.nlm.nih.gov/pmc/articles/PMC5182161/

WILLCUTT, Erik G. et al. Validity of the executive function theory of attentiondeficit/hyperactivity disorder: a meta-analytic review. Biological psychiatry, v. 57, n. 11, p. 1336-1346, 2005. Acesso: 29/10/2019 https://www.sciencedirect.com/science/article/abs/pii/S000632230500171X

\section{APÊNDICE - REFERÊNCIAS DE NOTA DE RODAPÉ}

3. Disponível em: https://www.otempo.com.br/infograficos/o-cerebro-de-quem-temtdah-1.2221666> Acesso em nov. 2019.

4. Disponível em: < https://br.pinterest.com/pin/733383120540847194/?lp=true > Acesso em nov. 2019.

Enviado: Fevereiro, 2020.

Aprovado: Fevereiro, 2020. 